\title{
Nitric oxide and the Kagome lattice
}

Laura J. McCormick, ${ }^{1,2}$ Lais W. Aguiar, ${ }^{1,3}$ Samuel A. Morris, ${ }^{1}$ Matthew J. McPherson, ${ }^{1}$ David. B. Cordes, ${ }^{1}$ Simon J. Teat, ${ }^{2}$ Alexandra M. Z. Slawin, ${ }^{1}$ Andrelson W. Rinaldi, ${ }^{3}$ Russell E. Morris ${ }^{1}$

1 School of Chemistry, University of St Andrews, St Andrews, U.K. KY16 9ST

2 Advanced Light Source, Lawrence Berkeley Lab, Berkeley, California, USA, 94720

3 Department of Chemistry, State University of Maringa-UEM, Maringa, Brazil

Kagome lattices derived from 5-substituted isophthalic acids (I, below) have been used as gas storage materials for $\mathrm{CO}$ and NO. ${ }^{1}$ The $\mathrm{NO}$ storage capacity of six previously unreported Kagome frameworks of composition $\mathrm{Cu}(\mathrm{Rip})\left(\mathrm{H}_{2} \mathrm{O}\right)\left(\mathrm{R}=\mathrm{Me}, \mathrm{MeO}\right.$, EtO, ${ }^{n} \mathrm{PrO},{ }^{n} \mathrm{BuO}$ or $\left.{ }^{i} \mathrm{BuO}\right)$ has been investigated. Unsurprisingly, the length of the substituent alkyl or alkoxy chain was found to influence the NO release capacity of these materials, however the shorter substituent chain derivatives displayed the highest surface area and the lowest NO release capacity. In situ dehydration studies on single crystals of $\mathrm{Cu}\left(\right.$ EtOip) $\left(\mathrm{H}_{2} \mathrm{O}\right)$ and $\mathrm{Cu}\left({ }^{n} \mathrm{PrOip}\right)\left(\mathrm{H}_{2} \mathrm{O}\right)$ were conducted and revealed that $\mathrm{Cu}$ (EtOip) $\left(\mathrm{H}_{2} \mathrm{O}\right)$ undergoes a single-crystal-to-single-crystal transformation upon evacuation at room temperature.

These $6 \mathrm{Cu}(\mathrm{Rip})\left(\mathrm{H}_{2} \mathrm{O}\right)$ materials have also been investigated for catalytic conversion of $\mathrm{NO}_{2}^{-}$to NO.<smiles>[R]c1cc(C(=O)O)cc(C(=O)O)c1</smiles>

\footnotetext{
${ }^{1}$ a) H. Sato, W. Kosaka, R. Matsuda, A. Hori, Y. Hijikata, R. V. Belosludov, S. Sakaki, M. Takata, S. Kitagawa, Science, 2014, 343, 167-170; b) M. I. H. Mohideen, B. Xiao, P. S. Wheatley, A. C. McKinlay, Y. Li, A. M. Z. Slawin, D. W. Aldous, N. F. Cessford,T. Düren, X. Zhao, R. Gill, K. M. Thomas, J. M. Griffin, S. E. Ashbrook, R. E. Morris, Nature Chemistry, 3, 304-310 (2011)
} 